\title{
Diamonds in the appendix
}

\author{
Haidar Alyaseen ${ }^{1 *} \mathbb{B}$, Ashraf Alnosair ${ }^{1}$, Mukhtar Alghanim² ${ }^{2}$ Ahmed Almusawi ${ }^{3}$ and Carlos Cordoba ${ }^{4}$
}

\begin{abstract}
Background: An uncommon cause of appendicitis is the entrapment of ingested foreign objects in the appendix. Although a rare event, it could remain asymptomatic for a prolonged time. The presence of foreign bodies in the gastrointestinal tract has a high potential for complications, in particular if sharp or large enough in size to cause obstruction. However, most often an ingested foreign object would be eliminated in the stool. Rarely, it may reside in the appendix depending on various factors such as the nature of the ingested body and the appendiceal peristaltic movements.

Case presentation: We report a case of abdominal pain due to a diamond earring trapped in the appendix for 2 years. A plain X-ray of the abdomen confirmed the diagnosis which prompted a laparoscopic appendectomy resulting in resolution of symptoms.

Conclusion: The initial presentation of an ingested foreign object can be similar to signs of symptoms of acute appendicitis and the patient must be monitored for several days to follow the trajectory of the foreign body in order to prevent complications. Even though the incidence is more common among the pediatric population, vigilance among adults should also be undertaken with a history of ingesting a foreign object, as this case demonstrates the importance of keeping a high index of suspicion when encountering such cases.
\end{abstract}

Keywords: Foreign body, Appendix, Pediatric, Earring, Case report, Laparoscopy

\section{Background}

Foreign body (FB) ingestion is a common scenario among children ages between 6 months and 6 years. Ingested objects depending on their shape, sharpness, size and nature differ in how they could injure the appendix wall if entrapped at this site [1]. Most ingested FBs are easily accessible in the child's environment. Among all ingested FBs, coins (61.7\%) occupy the highest frequency, followed by toys $(10.3 \%)$, jewelry $(7.0 \%)$, and batteries $(6.8 \%)$ [2]. Even though it is a common accidental occurrence, most ingested FBs pass through the body without causing any injuries [3]. About $1 \%$ are retained in the gastrointestinal tract [4].

Some of the ingested FBs may be the causative factor in alimentary tract obstruction or fistulas when they

\footnotetext{
*Correspondence: haider0555@windowslive.com

${ }^{1}$ Department of Surgery, Almoosa Specialist Hospital, Al Ahsa, Eastern Province, Kingdom of Saudi Arabia

Full list of author information is available at the end of the article
}

become lodged in the esophagus or the intestine. In the case of sharp rigid objects, they could tear the gastrointestinal lining resulting in perforations. Perforation arises in $70 \%$ and abscesses develop in $31 \%$, with ingested sharp tipped objects [5]. In rare cases, the effect of gravity leads the ingested FBs, with a higher density than the bowel content, into the appendix contributing to an obstruction. The position of the appendix and the failure of adequate appendicular peristalsis to push out the FB may lead to inflammation that can potentially cause perforation if left untreated [6].

\section{Case presentation}

A 5-year-old boy was referred to our surgery clinic at Almoosa Specialist Hospital in Al Ahsa, Saudi Arabia. He presented with recent occasional intermittent mild abdominal pain and a history of a FB ingestion that occurred 2 years prior to presenting at our clinic. On examination, vital signs were stable, the abdomen was soft without tenderness including over the right lower 
quadrant (RLQ), the bowel sounds were normal, rectal exam was unremarkable and occult blood negative. Labs were normal. Abdominal X-ray (Fig. 1A) revealed an irregular radiopaque (metallic) FB in the RLQ, without any other abnormalities.

The patient underwent elective abdominal laparoscopic exploration. Fluoroscopy was used to precisely locate the ingested object. The FB was found in the distal appendix. An appendectomy was performed and it was sent to histopathology. A diamond gold stud earring and clasp was extracted after dissection of the appendix (Fig. 1B). Histopathology showed no acute inflammation. The patient was discharged the following day and had an uneventful postoperative course.

\section{Discussion}

The management of gastrointestinal (GI) foreign bodies is routine observation. Sequential radiographs and stool follow-up are performed to confirm passage, unless it involves FB in the esophagus (FB lodged here should be removed), or FB consisting of batteries, sharp objects, long objects or magnets [7]. The majority of ingested FBs with a diameter less than $2.5 \mathrm{~cm}$ and a length less than $6 \mathrm{~cm}$ will within 5 days spontaneously pass through the gastrointestinal tract with excretion in the stools [8]. If they lodge in the intestines, it occurs around the curvature of the first part of the duodenum (duodenal sweep) and the physiologic narrowing just before the ileocecal valve [9].

In extremely rare cases, FBs may settle in the vermiform appendix [10-16]. These cases have been estimated to occur in $0.005 \%$ of ingested FBs [8]. Dr. Claudius Amyand performed the first successful appendectomy, at St. George's Hospital in London 286 years ago. The culprit was a swallowed pin lodged in the appendix causing perforation in an 11-year-old boy [17]. This is the first reported case in Saudi Arabia of an earring trapped in a pediatric appendix undetected for 2 years. The pathophysiology is not entirely clear, but it is believed that the characteristics of the FB plays an essential role in the occurrence of symptoms similar to acute appendicitis. If the FB is heavier than fecal matter, it may settle in the appendix due to gravity. The irregularity of the FB shape may also impede their evacuation by the peristaltic movements of the appendix. The size of the FB could occasionally obstruct the opening of the appendix. Examples of easily ingested objects that fit the above descriptions include balloons, toys with small parts, doll accessories, coins, safety pins, paperclips, pins, marbles, small balls, nails, bolts, and screws, erasers, batteries, broken crayons, jewelry (rings, earrings, pins, etc.), small magnets and small caps for bottles. Another factor contributing to this rare event is the relatively weak appendiceal peristalsis [8].

When a FB lodges itself, inflammation and edema are likely to occur as a result of increased intraluminal pressure leading to appendicitis. The consequences from not recognizing and failure to appropriately manage the early presentation may lead to complications varying from local infection, obstruction, perforation, peritonitis, septic shock and death. However, the course of these events does not develop suddenly, there may be signs that indicate something is brewing, starting from pain and tenderness over the RLQ to fever and abdominal distention and peritoneal signs.

Pediatric ingestions most commonly occur in the six months to six-year age range $[9,18-20]$ (https://colum

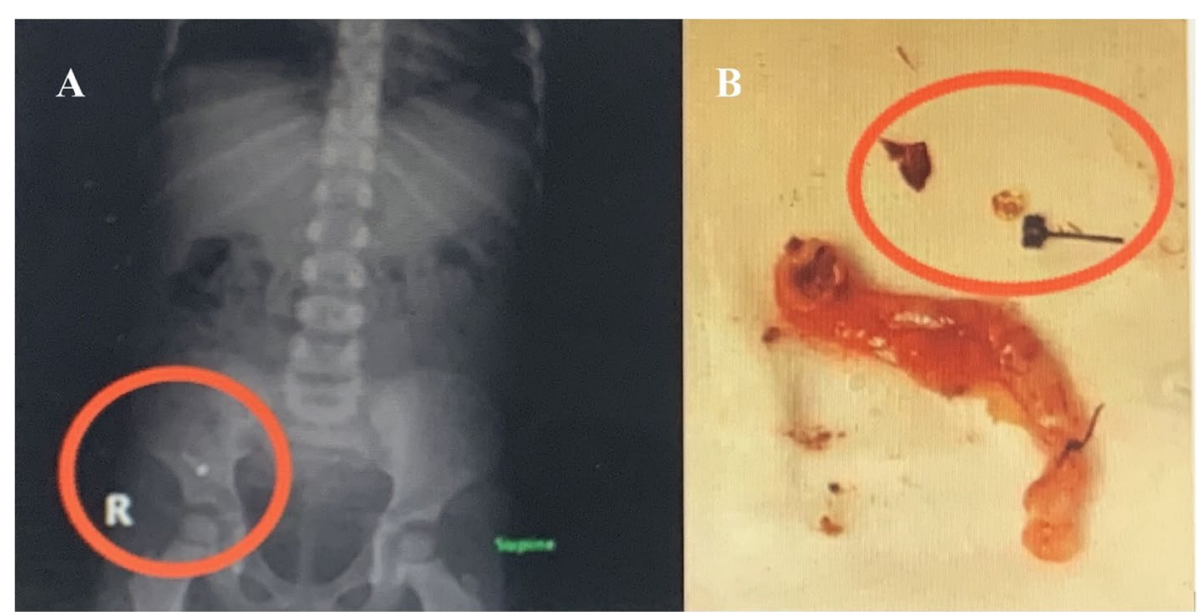

Fig. 1 A Evidence of RLQ radiopaque metallic foreign body. B Unremarkable appendix with luminal fecal material and a diamond gold metal stud earring with clasp FB detected on X-ray 
biasurgery.org/news/2015/06/04/ history-medicinemysterious-appendix). FB ingestion usually is initially asymptomatic in the pediatric population. Some FB may remain for long periods of time as in this case of a 2-year duration. Of note, $38 \%$ have reported recurrent pain for greater than a period of 1 month [5]. The majority of FB have an easy passage through the gastrointestinal tract. Nevertheless, the risk of complications remains present and proper management should be pursued. Most foreign bodies in the GI tract are radiopaque, therefore plain radiography as the first investigation is often diagnostic [21, 22]. When plain films are non-diagnostic, follow-up contrast radiography or CT is recommended [7]. In the majority of cases of trapped FB in the appendix, the X-ray does not show the specific location of the FB. With acute symptoms or a failed colonoscopy, laparoscopic exploration with the aid of the fluoroscope is the next course of action needed for the removal of the foreign objects $[23,24]$. In this case, laparoscopy was preferred over colonoscopy for the following reasons; the prolonged time period between the FB ingestion and the serial diagnostic $\mathrm{X}$-rays that suggested that the $\mathrm{FB}$ was not moving and the location of the FB; the high index of suspicion that the sharp pin-like object was trapped in the appendix; and the parents exaggerated perceived additional financial burden and risks of a CT and colonoscopy. The standard of care in such cases is serial diagnostic X-rays, followed by CT localization, if the FB is no longer migrating. Colonoscopy is initially recommended if the FB is found to be distal to the terminal ileum [23]. If the patient presented with acute symptoms or a failed attempt of retrieval via endoscopy, classical laparotomy and laparoscopic procedures are preferred [24] with or without the aid of intraoperative imaging. Identifying the exact location of the FB can save the patient unnecessary surgical exploration.

These cases have also been reported in adult patients [23], mainly found in the elderly, alcoholics, psychiatric patients, and prisoners [7]. In contrast to pediatric cases, adults are more likely to present with symptoms. It can be equally dangerous in adults as in children; however, not as prevalent.

\section{Conclusion}

It can be life-saving to educate parents and educators through public awareness campaigns about how to reduce swallowing and choking hazards around the home, nurseries and school by keeping small objects away from children. FB in the appendix is a very rare condition. The greatest factor of successful GI foreign body removal is radiographically pinpointing the object's exact location. However, if radiology indicates a foreign object in the abdomen, keep the appendix in mind as a possible location. A low threshold for surgery is suggested when there is a sharp rigid retained foreign body in the appendix as it may lead to an acute abdomen with perforation, abscess or appendicitis.

\section{Abbreviations \\ FB: Foreign body; RLQ: Right lower quadrant; Gl: Gastrointestinal.}

\section{Acknowledgements}

We would like to thank Almoosa Specialist Hospital and the Department of Surgery.

\section{Authors' contributions}

Conception of the work: CC. Data collection/literature review: HA/AsA/MA. Literature analysis and interpretation: HA/AsA/MA/AhA. Drafting the article: HA. Drawing/creating figures/tables: HA/AhA. Critical revision of the article: CC. Final approval of the version to be published: HA/AsA/MA/AhA/CC.

Funding

No funding source was associated with this study.

\section{Availability of data and materials}

There is no dataset. Not applicable.

\section{Declarations}

Ethics approval and consent to participate

Not applicable. The need for approval was not required.

Consent for publication

Parental consent to publish was obtained from the study participant.

\section{Competing interests}

All authors declare that they have no competing interests.

\section{Author details}

'Department of Surgery, Almoosa Specialist Hospital, Al Ahsa, Eastern Province, Kingdom of Saudi Arabia. ${ }^{2}$ King Faisal University College of Medicine, Al Ahsa, Eastern Province, Kingdom of Saudi Arabia. ${ }^{3}$ Imam Abdulrahman Bin Faisal University College of Medicine, Dammam, Eastern Province, Kingdom of Saudi Arabia. ${ }^{4}$ Department of Plastic Surgery, Almoosa Specialist Hospital, Al Ahsa, Eastern Province, Kingdom of Saudi Arabia.

Received: 16 July 2021 Accepted: 3 November 2021

Published online: 07 February 2022

\section{References}

1. Kramer RE, Lerner DG, Lin T, et al. Management of ingested foreign bodies in children: a clinical report of the NASPGHAN Endoscopy Committee. JPGN. 2015;60:562-74.

2. Orsagh-Yentis D, McAdams RJ, Roberts KJ, et al. Foreign-body ingestions of young children treated in US emergency departments: 1995-2015. Pediatrics. 2019;143(5):e20181988.

3. Panieri E, Bass DH. The management of ingested foreign bodies in children-a review of 663 cases. Eur J Emergency Med. 1995;2:83-7.

4. Selivanov V, Sheldon GF, Cello JP, Crass RA. Management of foreign body ingestion. Ann Surg. 1984;199(2):187-91. https://doi.org/10.1097/00000 658-198402000-00010

5. Balch CM, Silver D. Foreign bodies in the appendix. Report of eight cases and review of the literature. Arch Surg. 1971;102:14-21. 
6. Jang SO, Kim BS, Moon DJ. Application of Alvarado score in patients with suspected appendicitis. Korean J Gastroenterol. 2008;52:27-31.

7. Walls RM, Hockberger RS, Gausche-Hill M. Rosen's Emergency Medicine: Concepts and Clinical Practice. 9th Edition. 2017. 2-Volume Set. eBook ISBN: 9780323390163.

8. Cui J, Cross T, Lockwood D. Ingested razor blades within the appendix: a rare case report. Int I Surg Case Rep. 2018;45:29-32. https://doi.org/10. 1016/j.jijscr.2018.03.018.

9. ASGE Standards of Practice Committee, Ikenberry SO, Jue TL, Anderson MA, et al. Management of ingested foreign bodies and food impactions. Gastrointest Endosc. 2011;73:1085-91. https://doi.org/10.1016/j.gie.2010. 11.010 .

10. Doya L, Salhab N, Mansour HA, Alkhalil MAA. An unusual cause of appendectomy in a child (a sharp pin trapped in the appendix): a case report. Oxf Med Case Reports. 2020;2020(7). https://doi.org/10.1093/ omcr/omaa049.

11. Lambropoulos V, Fotoulaki M, Kepertis C, Neofytou A, Spyridakis I. An unusual foreign body within the appendix. Med J Malaysia. 2016;71(5):298-9.

12. Sama CB, Aminde LN, Njim TN, Angwafo FF 3rd. Foreign body in the appendix presenting as acute appendicitis: a case report. J Med Case Rep. 2016;10(1):129. https://doi.org/10.1186/s13256-016-0922-7.

13. Hartin CW Jr, Lau ST, Caty MG. Metallic foreign body in the appendix of 3-year-old boy. J Pediatr Surg. 2008;43(11):2106-8. https://doi.org/10. 1016/j.jpedsurg.2008.07.026

14. Nazzal K, Nazzal O, Ahmed A, Alaradi H, Alhindi S. Magnet beads impacted in the appendix of a child: a case report and review of the literature. Cureus. 2020 Aug 16;12(8):e9777. https://doi.org/10.7759/cureus. 9777.

15. Hulme P. Foreign body causing perforation of the appendix in an African boy. Pan Afr Med J. 2010;5:5. https://doi.org/10.4314/pamj.v5i1.56193.

16. Samujh R, Mansoor K, Khan I, Mannan A.' 'Screw'--appendicitis. Indian Pediatr. 2007:44(8):611-2.

17. Sarkar RR, Bisht J, Sinha Roy SK. Ingested metallic foreign body lodged in the appendix. J Indian Assoc Pediatr Surg. 2011 Jan;16(1):29-30. https:// doi.org/10.4103/0971-9261.74520.

18. Wyllie R. Foreign bodies in the gastrointestinal tract. Curr Opin Pediatr. 2006 Oct;18(5):563-4. https://doi.org/10.1097/01.mop.0000245359. 13949.1c

19. Uyemura MC. Foreign body ingestion in children. Am Fam Physician. 2005;72(2):287-91 Erratum in: Am Fam Physician. 2006 Apr 15;73(8):1332.

20. Cheng W, Tam PK. Foreign-body ingestion in children: experience with 1265 cases. J Pediatr Surg. 1999;34:1472-6.

21. Hachimi-Idrissi S, Come L, Vandenpias Y. Management of ingested foreign bodies in childhood: our experience and review of the literature. Eur J Emerg Med. 1998;5:319-23.

22. Pinto A, Lanza C, Pinto F, et al. Role of plain radiography in the assessment of ingested foreign bodies in the pediatric patients. Semin Ultrasound CT MR. 2015;36:21-7.

23. Klingler PJ, Seelig MH, DeVault KR, Wetscher GJ, Floch NR, Branton SA, et al. Ingested foreign bodies within the appendix: A 100-year review of the literature. Dig Dis. 1998;16(5):308-14. https://doi.org/10.1159/00001 6880.

24. Wnęk B, Łożyńska-Nelke A, Karoń J. Foreign body in the gastrointestinal tract leading to small bowel obstruction--case report and literature review. Pol Przegl Chir. 2015;86(12):594-7. https://doi.org/10.1515/ pjs-2015-0006.

\section{Publisher's Note}

Springer Nature remains neutral with regard to jurisdictional claims in published maps and institutional affiliations. 